\title{
Combating community resistance to care facilities
}

$\mathrm{O}$ pening care homes in established neighbourhoods is seldom an easy task, as local residents often lineup with emotional appeals against new facilities, even when it's been demonstrated they have an overall benefit to the community.

Such appeals are so common and often so contentious that the city of Saskatoon, Saskatchewan, has crafted a strategy to combat NIMBY ("not in my backyard") opposition to the development of residential care homes.

It's a move other Canadian cities should consider to curb "people zoning" and keep land use debates civil, social advocates argue, as the demand for residential care homes will only increase as the population ages.

Saskatoon's strategy, proposed in a report on policies governing care homes, aims to avert controversies by providing more information to residents of areas where new facilities are proposed so as to alleviate unfounded anxieties and focus public consultations.

"We want to hear what people have to say, but we want to keep the conversation focused on land use and not the land user," says Darryl Dawson, senior planner for the city's planning and development branch.

Community concerns over care homes - particularly those for people with mental disabilities - have run high in recent years, sparking ugly debates in communities across Canada, says Sharad Kerur, executive director of the Ontario Non-Profit Housing Association.

A group of Asian luxury condo owners in Vancouver, British Columbia, attracted national criticism in January for stalling plans to open a hospice near their building on the grounds that such a facility would negatively affect property values and bring bad luck.

Such concerns are often unsupported by fact, says Dawson. "Despite it being one of the most studied land use issues, there's zero evidence to suggest property values are negatively affected by the development of care homes."

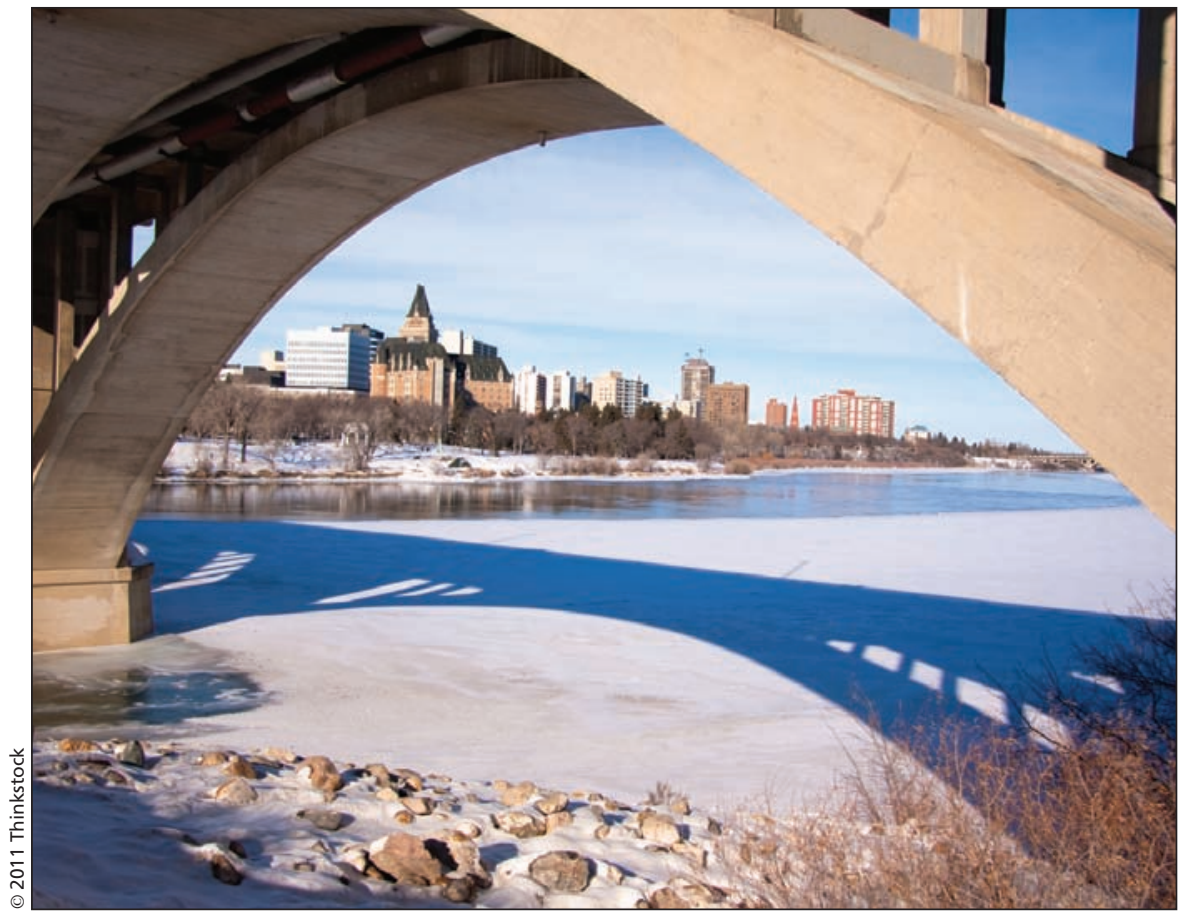

The city of Saskatoon, Saskatchewan has crafted a strategy to combat NIMBY ("not in my backyard") opposition to the development of residential care homes.

While youth homes generate more calls to police, most are related to "internal issues" based on the facilities" zero-tolerance policies, and have "no correlation" to an area increase in crime, Dawson adds. "If there are any issues in the home, they call the police. It's a function of how they operate."

When questioned in focus groups, people living beside existing care homes in Saskatoon were found to have few concerns about the facilities, outside of parking issues.

"There will always be concerns, but hopefully if we provide people with this information and the tools to evaluate the situation better ahead of time, it will mitigate a lot of the anxiety we see at public debates," says Dawson.

But as Saskatoon moves to curb "people zoning," Kerur says other municipalities have gone the opposite direction, imposing bylaws to limit the size of care homes or keep them out of select communities.

"There are a lot of policies and proce- dures that municipalities follow that they see as compromises, but that are incredibly discriminatory," says Phillip Dufresne, a nonprofit housing advocate who has lived 19 years in supportive housing in Toronto, Ontario. "They'll make us go to extra community meetings, or frost our windows, or remove our balconies or all kinds of things they wouldn't require other tenants to do."

As a resident, "it's demoralizing and it's intimidating," Dufresne adds. "But if you're living on the street, you can't do anything with your life. You need that housing to get a job, raise a family, develop an active social life, get the care you need and keep yourself healthy."

Dufresne is currently involved in legal cases challenging discriminatory bylaws in three Ontario cities: Kitchener, Sarnia and Toronto.

Implementing strategies to tackle NIMBY opposition could save such municipalities a lot of money in consultations and lost development opportunities, says Kerur. Such strategies would 
also help cities meet increased demand for care homes as the population ages, but many municipalities "just aren't there yet," he says.

Saskatoon's strategy will "clarify what elements of opposition should be considered, and responded to, during the approval process," in a bid to streamline consultation and keep costs to nonprofit developers down.

In addition, Saskatoon will develop a frequently asked questions sheet to distribute in neighbourhoods where new care homes are proposed and explore the use of moderators to keep public debates civil.

City officials also plan to promote the use of "good neighbour agreements" informal pacts between care home operators and neighbours that set expectations for things like parking and visiting hours, while providing all parties with contacts when disputes arise. Other Canadian cities, such as Calgary, Alberta, and Ottawa, Ontario, have successfully used such agreements to deal with community opposition to bars, clubs and homeless shelters, says Dawson.

The NIMBY strategy was tabled for review by Saskatoon City Council on Apr. 4. - Lauren Vogel, CMAJ

CMAJ 2011. DOI:10.1503/cmaj.109-3851 